Article

\title{
A Ladder-Type Organosilicate Copolymer Gate Dielectric Materials for Organic Thin-Film Transistors
}

\author{
Dongkyu Kim and Choongik Kim * \\ Department of Chemical and Biomolecular Engineering, Sogang University, Seoul 04107, Korea; \\ dgkim1993@gmail.com \\ * Correspondence: choongik@sogang.ac.kr; Tel.: +82-2-705-7964; Fax: +82-2-711-0439
}

Received: 31 May 2018; Accepted: 2 July 2018; Published: 3 July 2018

\begin{abstract}
A ladder-type organosilicate copolymer based on trimethoxymethylsilane (MTMS) and 1,2-bis(triethoxysilyl)alkane (BTESn: $n=2-4$ ) were synthesized for use as gate dielectrics in organic thin-film transistors (OTFTs). For the BTESn, the number of carbon chains (2-4) was varied to elucidate the relationship between the chemical structure of the monomer and the resulting dielectric properties. The developed copolymer films require a low curing temperature $\left(\approx 150{ }^{\circ} \mathrm{C}\right)$ and exhibit good insulating properties (leakage current density of $\approx 10^{-8}-10^{-7} \mathrm{~A} \cdot \mathrm{cm}^{-2}$ at $1 \mathrm{MV} \cdot \mathrm{cm}^{-1}$ ). Copolymer films were employed as dielectric materials for use in top-contact/bottom-gate organic thin-film transistors and the resulting devices exhibited decent electrical performance for both $\mathrm{p}$ - and n-channel organic semiconductors with mobility as high as $0.15 \mathrm{~cm}^{2} \cdot \mathrm{V}^{-1} \cdot \mathrm{s}^{-1}$ and an $I_{\text {on }} / I_{\text {off }}$ of $>10^{5}$. Furthermore, dielectric films were used for the fabrication of TFTs on flexible substrates.
\end{abstract}

Keywords: organic thin-film transistors; dielectric; organosilicate; copolymer

\section{Introduction}

Organic thin-film transistors (OTFTs) have been an important research subject because they are indispensable elements in the development of low-cost, large-area electronics, such as paper-based displays, smart cards, radio-frequency ID tags, and sensors [1-8]. Among the fundamental components of OTFTs, namely the semiconductor, dielectric, and conductor, studies on the development and application of organic semiconducting materials have intensively been performed for the last few decades [9-18]. Development of new dielectric materials for OTFTs, which perform as capacitors, insulators, and substrates, is also important to realize various electronic applications based on OTFTs. Favorable dielectric characteristics of OTFT-based electronic devices include ease of preparation, low cost, large area processibility, as well as excellent insulating properties [19-23].

Inorganic materials, such as $\mathrm{SiO}_{2}, \mathrm{Al}_{2} \mathrm{O}_{3}$, and $\mathrm{TiO}_{2}$, have traditionally been employed as dielectrics for OTFTs due to their excellent insulating properties. However, inorganic dielectric materials require a high-temperature/high-cost vacuum process for their preparation $[24,25]$. On the other hand, organic dielectric materials, such as polymers, can readily be processed from solution at a relatively low temperature over a large area, while their insulating properties are inferior to those of inorganic counterparts [26-28]. Furthermore, some organic-based dielectrics can be readily processed at low temperature, which can be employed on flexible substrates, such as polyethylene terephthalate (PET) and polyethylene naphthalate (PEN) [29-38].

To this end, many studies on the development and application of new dielectric materials with low leakage current, high dielectric constant, and facile process have been reported [39-48]. Among them, organic-inorganic hybrid dielectrics might synergistically combine the advantages of both materials, i.e., the excellent mechanical and electrical properties of inorganics and the flexibility and large area solution processibility of organics [41-44]. One of the representative examples is organosilicate 
materials, a type of silica containing organic groups. A few studies employing dielectric materials containing organosilicates have been reported for the fabrication of OTFTs [45-48].

For instance, Kang et al. reported silsesquioxane copolymer gate dielectrics based on methacryloxy propyltrimethoxysilane and phenyltrimethoxysilane for use in OTFTs. The reported dielectric films formed at a curing temperature of $200{ }^{\circ} \mathrm{C}$ exhibited a leakage current density as low as $6 \times 10^{-9} \mathrm{~A} \cdot \mathrm{cm}^{-2}$ at $1 \mathrm{MV} \cdot \mathrm{cm}^{-1}$ [45]. Similarly, Kim et al. reported dielectric materials based on a silsesquioxane derivative containing cage-structured epoxy groups, and the resulting films showed a leakage current density of $\approx 10^{-8} \mathrm{~A} \cdot \mathrm{cm}^{-2}$ at $1 \mathrm{MV} \cdot \mathrm{cm}^{-1}$ [46]. Lee et al. reported hybrid copolymer gate dielectrics based on methyltrimethoxysilane and 1,2-bis(trimethoxysilyl)ethane for use in OTFTs, with a leakage current density of $2.9 \times 10^{-6} \mathrm{~A} \cdot \mathrm{cm}^{-2}$ at $0.5 \mathrm{MV} \cdot \mathrm{cm}^{-1}$ [47]. Similarly, Hamada et al. reported on a polymethylsilsesquioxane (PMSQ) dielectric prepared by a sol-gel method from methyltrimethoxysilane. While the dielectric characteristic (leakage current density) was not reported in this study, the OTFTs based on the PMSQ dielectric showed very poor electrical performance with a mobility of $\approx 0.006 \mathrm{~cm}^{2} \cdot \mathrm{V}^{-1} \cdot \mathrm{s}^{-1}[48]$.

In this study, we report a ladder-type copolymer based on trimethoxymethylsilane (MTMS) and 1,2-bis(triethoxysilyl)alkane (BTESn) as dielectric materials. Previously reported organosilicate copolymer dielectric films based on similar monomers exhibited high leakage current density, resulting in relatively poor device characteristic for poly(3-hexylthiophene) (P3HT), possibly due to the unoptimized processing conditions [47]. Hence, we have optimized the synthesis and processing condition of copolymers by varying the monomer ratio, solvent, and employing different types of monomers. The copolymers were synthesized by a simple sol-gel reaction of two types of monomers, and curing was performed at a relatively low annealing temperature of $150{ }^{\circ} \mathrm{C}$. The resulting films exhibited a leakage current density of $10^{-8}-10^{-7} \mathrm{~A} \cdot \mathrm{cm}^{-2}$ at $1 \mathrm{MV} \cdot \mathrm{cm}^{-1}$ at a thickness of $\approx 100 \mathrm{~nm}$. Furthermore, the correlation between the dielectric properties of the copolymers and types of monomers was investigated by varying carbon chain lengths in BTESn. The OTFTs employing copolymer dielectrics were fabricated, and the resulting devices were active for both $\mathrm{p}$ - and n-channel organic semiconductors with carrier mobility as high as $0.15 \mathrm{~cm}^{2} \mathrm{~V}^{-1} \cdot \mathrm{s}^{-1}$ and a current on/off ratio of $\approx 10^{5}$ (Figure 1). Furthermore, we have employed the developed copolymer dielectric films on flexible substrate to fabricate flexible TFTs.
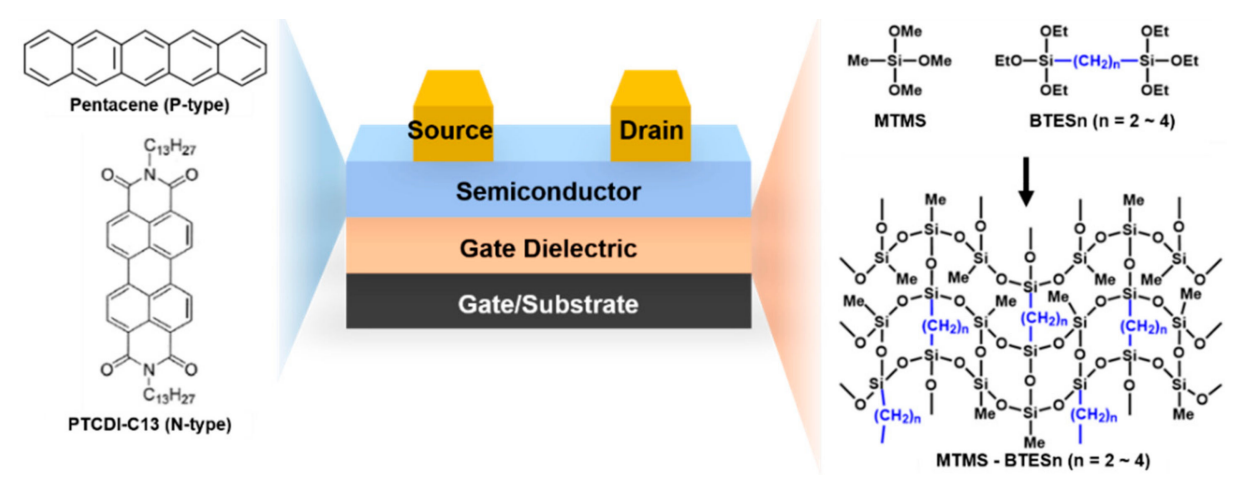

Figure 1. Schematic of top-contact/bottom-gate OTFT and chemical structures of organic semiconductors and dielectric materials employed in this study.

\section{Materials and Methods}

\subsection{Materials and Methods}

The semiconductors pentacene (P5) and $N, N^{\prime}$-Dioctyl-3,4,9,10-perylenedicarboximide (PTCDI-C13) were purchased from Sigma-Aldrich (St. Louis, MO, USA). Trimethoxymethylsilane (MTMS) and 1,2-bis(triethoxysilyl) ethane (BTES2), 1,2-bis(triethoxysilyl) propane (BTES3), 1,2-bis(triethoxysilyl) butane (BTES4) were purchased from Sigma-Aldrich (St. Louis, MO, USA). 
All materials were used without further purification. PEN substrates (Film Type Teonex Q65H, DuPont Teijin Films, Chester, VA, USA) were used as received without solvent cleaning. Structures of the MTMS-BTES $n$ were studied by ${ }^{1} \mathrm{H}$ NMR spectroscopy (Varian UNITY-INOVA $500 \mathrm{MHz}$ NMR spectrometer using Acetone- $\mathrm{d}_{6}$ as a solvent, Palo Alto, CA, USA) and Fourier transform infrared spectroscopy (FT-IR, Thermo Scientific Nicolet iS50R FTIR Spectrometer, Thermo Fisher Scientific, Waltham, MA, USA). Thermogravimetric analyses (TGA, TA Instrument Q50-1555, New Castle, DE, USA) were performed on each sample in a platinum crucible from 40 to $800{ }^{\circ} \mathrm{C}$ at a heating rate of $10{ }^{\circ} \mathrm{C} \min ^{-1}$ under an $\mathrm{N}_{2}$ atmosphere.

\subsection{Synthesis}

\subsubsection{Synthesis of MTMS-BTES2}

Trimethoxymethylsilane (5.11 g, $37.5 \mathrm{mmol}$ ) and 1,2-bis (triethoxysilyl) ethane ( $4.43 \mathrm{~g}, 12.5 \mathrm{mmol})$ were added to anhydrous tetrahydrofuran $(25 \mathrm{~mL})$ and stirred at room temperature for $30 \mathrm{~min}$. To this solution was added a $2 \mathrm{~N}$ aqueous hydrochloric acid solution $(0.75 \mathrm{~mL})$ and distilled water $(8.32 \mathrm{~mL})$, and the mixture was stirred at $40^{\circ} \mathrm{C}$ for $6 \mathrm{~h}$ under a nitrogen atmosphere to perform a sol-gel reaction. The reaction mixture was cooled to room temperature, and the organosilicate precursor synthesized from the solution was extracted with diethyl ether $(50 \mathrm{~mL})$. The extracted precursor solution was washed twice with distilled water, and then dried under vacuum at room temperature for $1 \mathrm{~h}$ to remove the solvent to obtain a white powdery solid. The solids were again dissolved in acetone $(200 \mathrm{~mL})$ to afford the gelation of the organosilicate, and undissolved particles were removed by filtration. The solution was dried under vacuum at room temperature for $12 \mathrm{~h}$ using a rotary evaporator to remove residual solvent, and a white solid $(3.97 \mathrm{~g}, 41.61 \%)$ was obtained again. ${ }^{1} \mathrm{H}-\mathrm{NMR}(500 \mathrm{MHz}$, Acetone- $\left.\mathrm{d}_{6}\right): \delta 0.19(\mathrm{~s}, 3 \mathrm{H}), 0.90(\mathrm{~s}, 2 \mathrm{H}), 5.70(\mathrm{~s}, \mathrm{H})$.

\subsubsection{Synthesis of MTMS-BTES3}

Trimethoxymethylsilane ( $5.11 \mathrm{~g}, 37.5 \mathrm{mmol}$ ) and 1,2-bis (triethoxysilyl) propane ( $4.61 \mathrm{~g}, 12.5 \mathrm{mmol}$ ) were added to anhydrous tetrahydrofuran $(25 \mathrm{~mL})$ and stirred at room temperature for $30 \mathrm{~min}$. To this solution was added a $2 \mathrm{~N}$ aqueous hydrochloric acid solution $(0.75 \mathrm{~mL})$ and distilled water $(8.32 \mathrm{~mL})$, and the mixture was stirred at $40{ }^{\circ} \mathrm{C}$ for $6 \mathrm{~h}$ under a nitrogen atmosphere to perform a sol-gel reaction. The next purification processes were same as those of MTMS-BTES2 and a white solid (4.43 g, 45.58\%) was obtained. ${ }^{1} \mathrm{H}-\mathrm{NMR}\left(500 \mathrm{MHz}\right.$, Acetone- $\left.\mathrm{d}_{6}\right): \delta 0.19(\mathrm{~s}, 3 \mathrm{H}), 0.90(\mathrm{~s}, 2 \mathrm{H}), 1.71(\mathrm{~s}, 2 \mathrm{H}), 5.70(\mathrm{~s}, \mathrm{H})$.

\subsubsection{Synthesis of MTMS-BTES4}

Trimethoxymethylsilane (5.11 g, $37.5 \mathrm{mmol}$ ) and 1,2-bis (triethoxysilyl) butane (4.78 g, $12.5 \mathrm{mmol})$ were added to anhydrous tetrahydrofuran $(25 \mathrm{~mL})$ and stirred at room temperature for $30 \mathrm{~min}$. To this solution was added a $2 \mathrm{~N}$ aqueous hydrochloric acid solution $(0.75 \mathrm{~mL})$ and distilled water $(8.32 \mathrm{~mL})$, and the mixture was stirred at $40^{\circ} \mathrm{C}$ for $6 \mathrm{~h}$ under a nitrogen atmosphere to perform a sol-gel reaction. The next purification processes were same as those of MTMS-BTES2 and a white solid $(4.68 \mathrm{~g}, 47.32 \%)$ was obtained. ${ }^{1} \mathrm{H}-\mathrm{NMR}\left(500 \mathrm{MHz}\right.$, Acetone- $\left.\mathrm{d}_{6}\right): \delta 0.19(\mathrm{~s}, 3 \mathrm{H}), 0.90(\mathrm{~s}, 2 \mathrm{H}), 1.71(\mathrm{~s}, 2 \mathrm{H}), 5.70(\mathrm{~s}, \mathrm{H})$.

\subsection{Film Preparation and Device Fabrication}

Top-contact/bottom-gate organic thin-film transistor devices were fabricated using highly n-doped silicon wafers (resistivity $<0.005 \Omega \cdot \mathrm{cm}$ ) as gate/substrates. The substrates were cleaned by sonication in isopropyl alcohol for $20 \mathrm{~min}$, followed by $\mathrm{O}_{2}$ plasma for $5 \mathrm{~min}$ (Harrick Plasma, 18W, Ithaca, NY, USA). For the fabrication of devices on flexible substrates, the bottom Al gate electrodes were thermally evaporated through a shadow mask on the polyethylene naphthalate (PEN) substrate. For the preparation of a gate dielectric layer, MTMS-BTES $n(n=2-4)$ was dissolved in propylene glycol monomethyl ether acetate (PGMEA) solvent at $10 \mathrm{wt} . \%$. The resulting solutions were dropped on a silicon wafer or PEN substrates with Al gate electrodes through a syringe equipped with a $0.2 \mu \mathrm{m}$ 
polytetrafluoroethylene (PTFE) filter, and then spun at $3000 \mathrm{rpm}$ for $30 \mathrm{~s}$. The spin-coated films were annealed at $150{ }^{\circ} \mathrm{C}$ for $2 \mathrm{~h}$ under nitrogen. Film thicknesses were $80-150 \mathrm{~nm}$, as characterized by an ellipsometer. A $40 \mathrm{~nm}$ thick P5 or PTCDI-C13 film was deposited onto the prepared MTMS-BTESn copolymer gate dielectrics at a rate of $0.2 \AA \cdot \mathrm{s}^{-1}\left(\approx 10^{-5}\right.$ Torr $)$. Finally, a gold source and drain electrode $(40 \mathrm{~nm})$ was thermally evaporated through a shadow mask with channel lengths $(\mathrm{L}, 50-100 \mu \mathrm{m})$ and width (W, 1000-2000 $\mu \mathrm{m})$.

Metal/insulator/semiconductor (MIS) structures were fabricated using highly n-doped silicon wafers as a gate/substrate. Then the organosilicate copolymer dielectric was spin-coated and annealed at $150{ }^{\circ} \mathrm{C}$ for $2 \mathrm{~h}$, as described above. Finally, gold top electrodes $(40 \mathrm{~nm})$ were thermally deposited. The area of the testing capacitor was $0.2 \mathrm{~mm} \times 0.2 \mathrm{~mm}$.

\subsection{Film and Device Characterization}

Film thicknesses were characterized by ellipsometer (Filmetrics, F20, San Diego, CA, USA). The surface morphologies of copolymer thin films were characterized by atomic force microscope (AFM, NX10, Park Systems, Suwon, South Korea). A Keithley 4200 SCS (Cleveland, OH, USA) was used for the characterization of OTFTs and leakage current measurements. The capacitance measurement of copolymer thin films were performed using an LCR meter (Agilent 4284A, Agilent Technologies, Santa Clara, CA, USA). Carrier mobilities $(\mu)$ were determined in the saturation regime using the standard relationship, $\mu_{\text {sat }}=\left(2 I_{D S} L\right) /\left[W C_{i}\left(V_{G}-V_{T}\right)^{2}\right]\left(I_{D S}\right.$, source-drain current; $L$, the channel length; $W$, channel width; $C_{i}$, areal capacitance of the gate dielectric; $V_{G}$, gate voltage; $V_{T}$, threshold voltage).

\section{Results}

\subsection{Synthesis}

MTMS-BTES $n$ copolymers were prepared using a sol-gel reaction of MTMS and BTESn, and were characterized by ${ }^{1} \mathrm{H}-\mathrm{NMR}$ and FT-IR (Figures S1 and S2). As shown in the NMR spectra (Figure S1), the MTMS monomer was confirmed by the pendant methyl group peak at $\approx 0.08-0.2 \mathrm{ppm}$. The BTESn monomer was confirmed by ethylene bridge structure peak formed at $0.8 \mathrm{ppm}$. BTES3 and BTES4 were additionally confirmed at $\approx 1.6 \mathrm{ppm}$ using a bridge structure peak. Note that the peak at $\approx 6 \mathrm{ppm}$ is from the residual hydroxide group formed during the polymerization. The network structure formed between MTMS and BTES $n$ can be confirmed by FT-IR spectra (Figure S2). Two absorption peaks at 1131 and $1040 \mathrm{~cm}^{-1}$, corresponding to $\mathrm{Si}-\mathrm{O}-\mathrm{Si}$ stretching vibrations, were observed in all samples. The bimodal absorption peaks indicate the formation of ladder-type structures [49-51].

\subsection{Dielectric Characterization}

The MTMS-BTES $n$ copolymer film was formed via spin-coating onto a substrate to a thickness of $\approx 80-150 \mathrm{~nm}$, as measured by an ellipsometer. First, the surface morphologies of the dielectric films were characterized using an AFM, and a relatively smooth surface (root-mean-square roughness: 0.4-1.0 nm) was observed, regardless of the film thickness (Figure 2).

Then, the leakage current density and areal capacitance of the dielectric films were measured based on the MIS structure with Au top electrodes (Table 1 and Figure 3). First, all dielectric films showed a low leakage current density of $\approx 10^{-8}-10^{-7} \mathrm{~A} \cdot \mathrm{cm}^{-2}$ at $1 \mathrm{MV} \cdot \mathrm{cm}^{-1}$ (Figure 3a). Although there was no significant difference with regard to the type of monomer, the leakage current density slightly increased as the number of carbon atoms of BTES $n$ increased (Figure 3c). The methyl groups in the MTMS might reduce the relative amount of hydroxyl groups during the sol-gel reaction and increase the stability of the film [37]. Also, electrical stability of the dielectric can be enhanced by reducing the free volume due to the low curing temperature of $150{ }^{\circ} \mathrm{C}$ and by limiting the thermal dynamic motion of the polymer chains due to the sol-gel bonded network structure. 


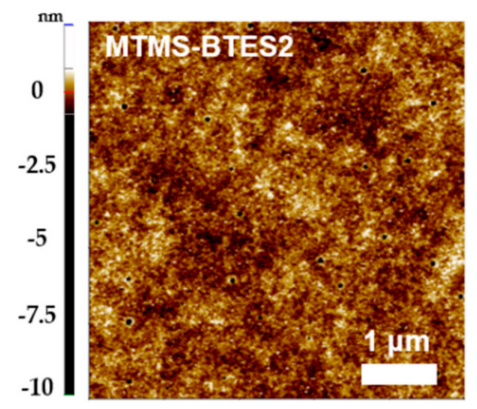

(a)

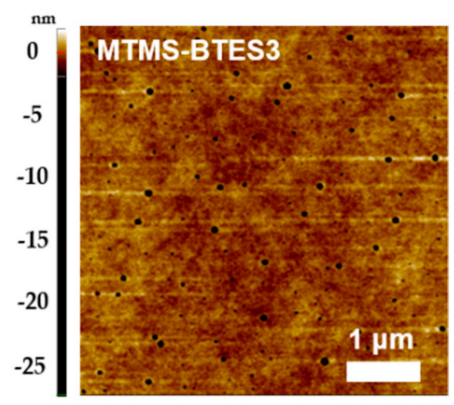

(b)

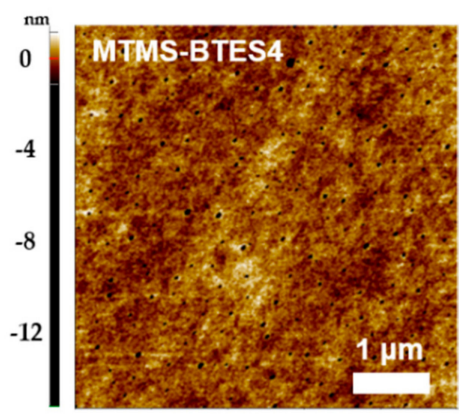

(c)

Figure 2. AFM images $(5 \mu \mathrm{m} \times 5 \mu \mathrm{m})$ of MTMS-BTESn copolymer gate dielectric films: (a) MTMS-BTES2, (b) MTMS-BTES3, and (c) MTMS-BTES4.

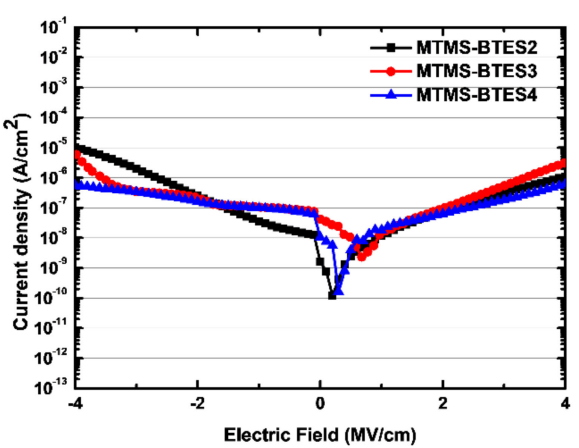

(a)

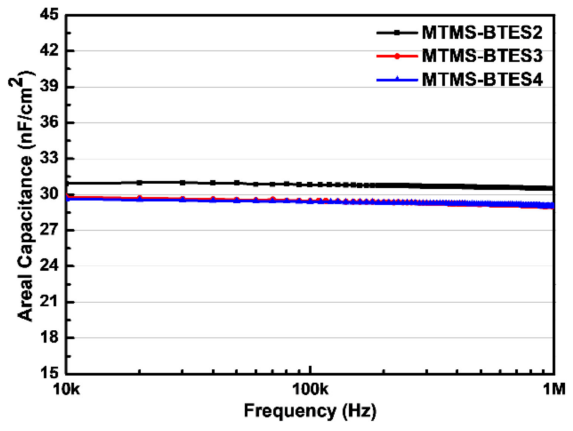

(b)

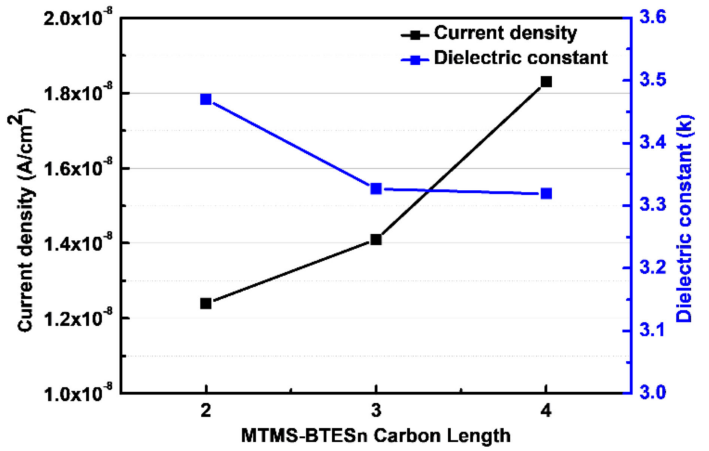

(c)

Figure 3. Electrical properties of spin-coated copolymer films fabricated with various monomers (thickness: $100 \mathrm{~nm}$ ): (a) Leakage current density vs electric field plot; (b) Capacitance-frequency plots $\left(10-10^{3} \mathrm{kHz}\right)$; (c) Comparison of leakage current density and $\mathrm{k}$ value as a function of monomer type. 
Table 1. Properties of Copolymer Dielectrics based on MIS Device Structure ( $J$, leakage current density; $C_{i}$, Capacitance; $k$, dielectric constants).

\begin{tabular}{|c|c|c|c|c|}
\hline Copolymer & $\begin{array}{c}\text { Thickness } \\
\text { (nm) }\end{array}$ & $\begin{array}{c}J\left(\mathrm{~A} \cdot \mathrm{cm}^{-2}\right) \text { at } \\
1 \mathrm{MV} \cdot \mathrm{cm}^{-1}\end{array}$ & $C_{i}\left(\mathrm{nF} \cdot \mathrm{cm}^{-2}\right)$ & $k$ \\
\hline \multirow{3}{*}{ MTMS-BTES2 } & 140 & $8.11 \times 10^{-8}$ & 23.0 & 3.60 \\
\hline & 100 & $1.24 \times 10^{-8}$ & 30.8 & 3.47 \\
\hline & 80 & $1.38 \times 10^{-7}$ & 33.6 & 3.33 \\
\hline \multirow{3}{*}{ MTMS-BTES3 } & 135 & $3.91 \times 10^{-8}$ & 23.3 & 3.50 \\
\hline & 102 & $1.41 \times 10^{-8}$ & 29.5 & 3.33 \\
\hline & 90 & $1.20 \times 10^{-8}$ & 32.2 & 3.27 \\
\hline \multirow{3}{*}{ MTMS-BTES4 } & 150 & $5.27 \times 10^{-8}$ & 20.5 & 3.47 \\
\hline & 113 & $6.55 \times 10^{-8}$ & 29.1 & 3.31 \\
\hline & 100 & $1.83 \times 10^{-8}$ & 29.4 & 3.32 \\
\hline
\end{tabular}

In the case of the capacitance measurement, the measurement was performed between 10 and $10^{3} \mathrm{kHz}$. As the frequency increased, the capacitance value decreased slightly. Based on the capacitance value at $10^{2} \mathrm{kHz}$, the dielectric constants were 3.3-3.5, which is similar to the conventional organosilicate-based materials [35-37]. For the dielectric films with comparable thickness, as the number of carbon in the monomers increased, the value of $k$ decreased, which could be a result of the increased free volume of monomers with more carbon chains.

\subsection{Thin-Film Transistor Fabrication and Characterization}

We fabricated OTFTs by spin-coating MTMS-BTESn materials on the $\mathrm{n}^{++}-\mathrm{Si}$ gate/substrate, followed by annealing at $150^{\circ} \mathrm{C}$ for $2 \mathrm{~h}$. P-type (P5) and n-type (PTCDI-C13) organic semiconductors were vacuum-deposited onto the copolymer dielectric layer, followed by Au source/drain electrodes. The device characteristics including carrier mobilities in the saturation regime $\left(\mu_{\text {sat }}\right)$, and current on/off ratios $\left(I_{o n} / I_{\text {off }}\right)$, and threshold voltage $\left(V_{T}\right)$ are shown in Table 2. Transfer characteristics of the devices were measured in the saturation regime $\left(V_{D S} \geq V_{G}-V_{T}\right)$, and representative transfer plots are shown in Figure 4. As shown, the OTFT devices operated well for both p-and n-channel organic semiconductors with a carrier mobility as high as $0.15 \mathrm{~cm}^{2} \cdot \mathrm{V}^{-1} \cdot \mathrm{s}^{-1}$ and $I_{\text {on }} / I_{\text {off }}$ of $>10^{5}$. Furthermore, copolymer dielectric films could be employed on flexible PEN substrates, due to the low curing temperature, and the resulting OTFT device showed a slightly lower performance than that on a rigid substrate with an electron mobility of $0.04 \mathrm{~cm}^{2} \cdot \mathrm{V}^{-1} \cdot \mathrm{s}^{-1}$ for the PTCDI-C13 semiconductor (Figure 5).

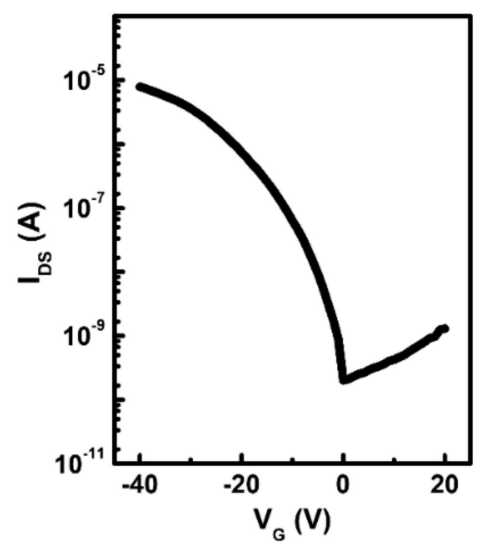

(a)

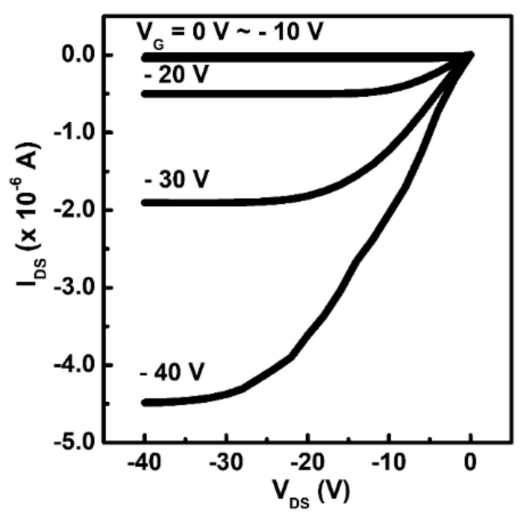

(b)

Figure 4. Cont. 


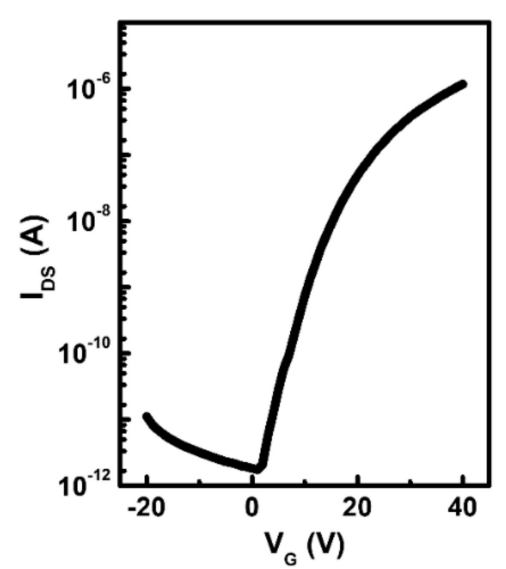

(c)

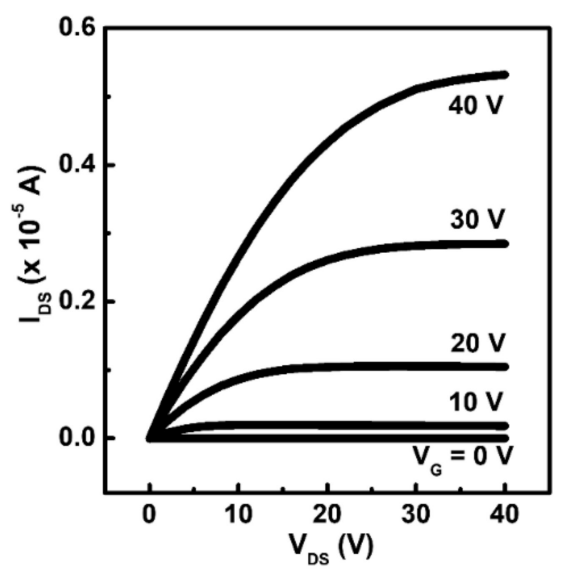

(d)

Figure 4. Performance of OTFT devices on copolymer dielectric films. OTFT transfer characteristics for (a) P5, (c) PTCDI-C13, and OTFT output characteristics for (b) P5, (d) PTCDI-C13. The channel width and length are 1000 and $100 \mu \mathrm{m}$, respectively.

Table 2. TFT Device Performance Parameters based on P5 and PTCDI-C13 Semiconductors on Copolymer Dielectric. ( $\mu_{\text {sat }}$ : carrier mobility, $I_{o n} / I_{\text {off: }}$ current on/off ratio, $V_{T}$; threshold voltage).

\begin{tabular}{|c|c|c|c|c|}
\hline Type & Semi-Conductor & $\begin{array}{c}\mu_{\text {sat }} \\
{ }^{\mathbf{1}}\left(\mathrm{cm}^{2} \cdot \mathrm{V}^{-1} \cdot \mathrm{s}^{-1}\right)\end{array}$ & $I_{o n} / I_{o f f}$ & $V_{T}(\mathrm{~V})$ \\
\hline p-type & P5 & 0.15 & $2.24 \times 10^{5}$ & -10.5 \\
\hline n-type & PTCDI-C13 & 0.09 & $3.00 \times 10^{6}$ & 9.3 \\
\hline
\end{tabular}

${ }^{1}$ The average values obtained from six different devices.

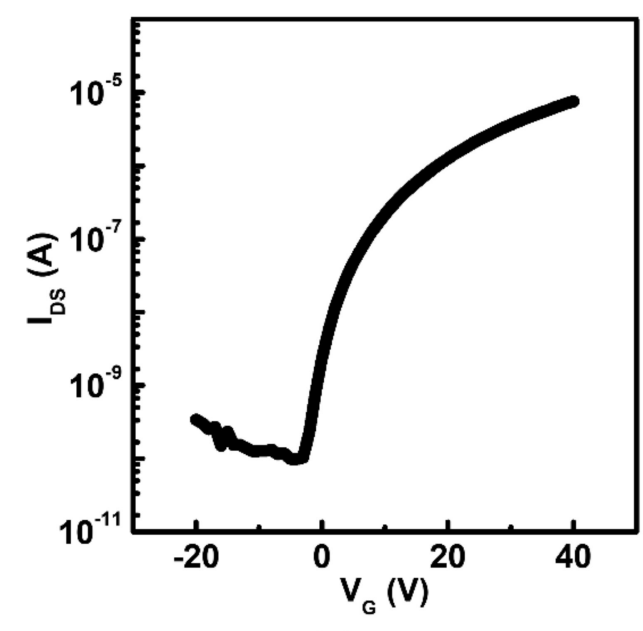

(a)

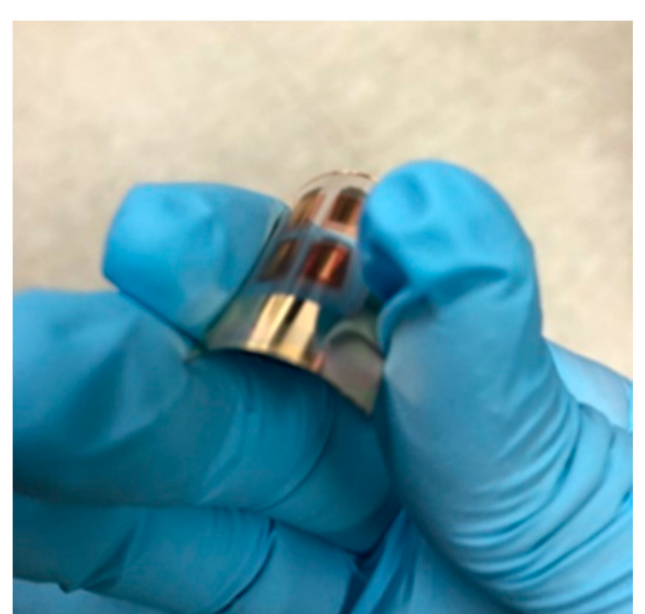

(b)

Figure 5. OTFT devices fabricated on flexible PEN substrates. (a) Transfer characteristics using a PTCDI-C13 as semiconductor (channel width and length are 2000 and $50 \mu \mathrm{m}$, respectively); (b) Photo of flexible OTFT device.

\section{Conclusions}

This article explored the dielectric characteristics of a copolymer based on MTMS and BTESn with various carbon numbers. Organosilicate copolymer dielectrics with various lengths of carbon chains could be easily prepared by the sol-gel method. Despite the existence of natural free volume due to the 
difference of compatibility between organic and inorganic materials, a good insulating property of copolymer dielectrics was observed. All three types of dielectric films exhibited a relatively smooth surface and low leakage current density of $\approx 10^{-8}-10^{-7} \mathrm{~A} \cdot \mathrm{cm}^{-2}$ at $1 \mathrm{MV} \cdot \mathrm{cm}^{-1}$ via the optimization of processing conditions and monomer components. With regard to different chemical structure of monomers, the leakage current density increased slightly, while dielectric constant value decreased, as the number of carbon atoms in BTESn increased, possibly due to the structural free volume caused by the carbon bridge. The copolymer films were employed as a dielectric layer for OTFTs, and the resulting devices were active for both $\mathrm{p}$ - and $\mathrm{n}$-channel organic semiconductors with a carrier mobility as high as $0.15 \mathrm{~cm}^{2} \cdot \mathrm{V}^{-1} \cdot \mathrm{s}^{-1}$ and $I_{\text {on }} / I_{\text {off }}$ of $\approx 10^{5}$.

Supplementary Materials: The following are available online at http:/ /www.mdpi.com/2079-6412/8/7/236/s1, Figure S1: ${ }^{1} \mathrm{H}-\mathrm{NMR}$ analysis of MTMS-BTES $n$ copolymer, Figure S2: Fourier transform infrared spectroscopy (FT-ir) of MTMS-BTES $n$ copolymer

Author Contributions: D.K. and C.K. designed the experiments. D.K. performed the experiments. D.K. and C.K. wrote the paper.

Funding: This research was funded by the National Research Foundation of Korea (NRF) (NRF-2017R1A2B4001955 and NRF-2017M2B2A4049297).

Conflicts of Interest: The authors declare no conflict of interest.

\section{References}

1. Ortiz, R.P.; Facchetti, A.; Marks, T.J. High-k Organic, Inorganic, and Hybrid Dielectrics for Low-Voltage Organic Field-Effect Transistors. Chem. Rev. 2010, 110, 205-239. [CrossRef] [PubMed]

2. Kang, B.S.; Lee, W.H.; Cho, K.W. Recent Advances in Organic Transistor Printing Processes. ACS Appl. Mater. Interfaces 2013, 5, 2302-2315. [CrossRef] [PubMed]

3. Forrest, S.B. The path to ubiquitous and low-cost organic. Nature 2004, 428, 911-918. [CrossRef] [PubMed]

4. Yi, H.T.; Payne, M.M.; Anthony, J.E.; Podzorov, V. Ultra-flexible solution-processed organic field-effect transistors electronic appliances on plastic. Nat. Commun. 2012, 3, 1259-1265. [CrossRef] [PubMed]

5. Ozdemir, M.; Choi, D.H.; Kwon, G.H.; Zorlu, Y.; Cosut, B.; Kim, H.K.; Facchetti, A.; Kim, C.I.; Usta, H. Solution-Processable BODIPY-Based Small Molecules for Semiconducting Microfibers in Organic Thin-Film Transistors. ACS Appl. Mater. Interfaces 2016, 8, 14077-14087. [CrossRef] [PubMed]

6. Sirringhaus, H. 25th Anniversary Article: Organic Field-Effect Transistors: The Path Beyond Amorphous Silicon. Adv. Mater. 2014, 26, 1319-1335. [CrossRef] [PubMed]

7. Cowen, L.M.; Atoyo, J.; Carnie, M.J.; Baran, D.; Schroeder, B.C. Review—Organic Materials for Thermoelectric Energy Generation. ECS J. Solid State Sci. Technol. 2017, 6, 3080-3088. [CrossRef]

8. Pierre, A.; Sadeghi, M.; Payne, M.M.; Facchetti, A.; Anthony, J.E.; Arias, A.C. All-Printed Flexible Organic Transistors Enabled by Surface Tension-Guided Blade Coating. Adv. Mater. 2014, 26, 5722-5727. [CrossRef] [PubMed]

9. Heitzer, H.M.; Marks, T.J.; Ratner, M.A. Molecular Donor-Bridge-Acceptor Strategies for High-Capacitance Organic Dielectric Materials J. Am. Chem. Soc. 2015, 137, 7189-7196. [CrossRef] [PubMed]

10. Yan, Y.; Huang, L.B.; Zhou, Y.; Han, S. T; Zhou, L.; Sun, Q.; Zhuang, J.; Peng, H.; Yan, H.; Roy, V.A.L. Surface Decoration on Polymeric Gate Dielectrics for Flexible Organic Field-Effect Transistors via Hydroxylation and Subsequent Monolayer Self-Assembly. ACS Appl. Mater. Interfaces 2015, 7, 23464-23471. [CrossRef] [PubMed]

11. Jiang, Y.; Guo, Y.; Liu, Y. Engineering of Amorphous Polymeric Insulators for Organic Field-Effect Transistors. Adv. Electron. Mater. 2017, 3, 1700157. [CrossRef]

12. Kim, H.K.; Reddy, M.R.; Kim, H.S.; Choi, D.H.; Kim, C.I.; Seo, S.Y. Benzothiadiazole-Based Small-Molecule Semiconductors for Organic Thin-Film Transistors and Complementary-like Inverters. ChemPlusChem 2017, 82, 742-749. [CrossRef]

13. Ozdemir, M.; Choi, D.H.; Zorlu, Y.; Cosut, B.; Kim, H.S.; Kim, C.I.; Usta, H. A new rod-shaped BODIPY-acetylene molecule for solution-processed semiconducting microribbons in n-channel organic field-effect transistors. New J. Chem. 2017, 41, 6232-6240. [CrossRef] 
14. Ozdemir, R.; Choi, D.H.; Ozdemir, M.; Kim, H.K.; Kostakoglu, S.T.; Erkartal, M.; Kim, H.S.; Kim, C.I.; Usta, H. A Solution-Processable Liquid-Crystalline Semiconductor for Low-Temperature-Annealed Air-Stable N-Channel Field-Effect Transistors. ChemPhysChem 2017, 18, 850-861. [CrossRef] [PubMed]

15. Vegiraju, S.; He, G.Y.; Kim, C.I.; Priyanka, P.; Chiu, Y.J.; Liu, C.W.; Huang, C.Y.; Ni, J.S.; Wu, Y.W.; Chen, Z.; et al. Solution-Processable Dithienothiophenoquinoid (DTTQ) Structures for Ambient-Stable n-Channel Organic Field Effect Transistors. Adv. Funct. Mater. 2017, 27, 1606761. [CrossRef]

16. Ozdemir, M.; Kim, S.W.; Kim, H.S.; Kim, M.G.; Kim, B.J.; Kim, C.I.; Usta, H. Semiconducting Copolymers Based on meso-Substituted BODIPY for Inverted Organic Solar Cells and Field-Effect Transistors. Adv. Electron. Mater. 2017, 1700354. [CrossRef]

17. Ho, D.I.; Jeon, M.S.; Kim, H.K.; Gidron, O.; Kim, C.I.; Seo, S.Y. Solution-processable dithieno [3,2-b:2' ,3'-d] thiophene derivatives for organic thin-film transistors and complementary-like inverters. Org. Electron. 2018, 52, 356-363. [CrossRef]

18. Reddy, M.R.; Kim, H.S.; Kim, C.I.; Seo, S.Y. 2-Thiopene [1] benzothieno [3,2-b] benzothiophene derivatives as solution processable organic semiconductors for organic thin-film transistors. Synth. Met. 2018, 235, $153-159$. [CrossRef]

19. Bao, Z.; Chen, X. Flexible and Stretchable Devices. Adv. Mater. 2016, 18, 4177-4179. [CrossRef] [PubMed]

20. Nela, L.; Tang, J.; Cao, Q.; Tulevski, G.; Han, S.J. Large-Area High-Performance Flexible Pressure Sensor with Carbon Nanotube Active Matrix for Electronic Skin. Nano Lett. 2018, 18, 2054-2059. [CrossRef] [PubMed]

21. Lei, T.; Pochorovski, I.; Bao, Z. Separation of Semiconducting Carbon Nanotubes for Flexible and Stretchable Electronics Using Polymer Removable Method. Acc. Chem. Res. 2017, 50, 1096-1104. [CrossRef] [PubMed]

22. Joe, D.J.; Kim, S.J.; Park, J.H.; Park, D.Y.; Lee, H.E.; Im, T.H.; Choi, I.S.; Ruoff, R.S.; Lee, K.J. Laser-Material Interactions for Flexible Applications. Adv. Mater. 2017, 29, 1606586. [CrossRef] [PubMed]

23. Myny, K. The development of flexible integrated circuits based on thin-film transistors. Nat. Electron. 2018, 1, 30-39. [CrossRef]

24. Ha, T.J.; Sonar, P.; Dodabalapur, A. Improved Performance in Diketo pyrrolopyrrole-Based Transistors with Bilayer Gate Dielectrics. ACS Appl. Mater. Interfaces 2014, 6, 3170-3175. [CrossRef] [PubMed]

25. Tardy, J.; Erouel, M.; Deman, A.L.; Gagnaire, A.; Teodorescu, V.; Blanchin, M.G.; Canut, B.; Barau, A.; Zaharescu, M. Organic thin film transistors with $\mathrm{HfO}_{2}$ high-k gate dielectric grown by anodic oxidation or deposited by sol-gel. Microelectron. Reliab. 2007, 47, 372-377. [CrossRef]

26. Li, S.X.; Feng, L.R.; Guo, X.J.; Zhang, Q. Application of thermal azide-alkyne cycloaddition(TAAC) reaction as a low temperature cross-linking method in polymer gate dielectrics for organic field-effect transistors. J. Mater. Chem. C 2014, 2, 3517-3520. [CrossRef]

27. Puigdollers, J.; Voz, C.; Orpella, A.; Quidant, R.; Martin, I.; Vetter, M.; Alcubilla, R. Pentacene thin-film transistors with polymeric gate dielectric. Org. Electron. 2004, 5, 67-71. [CrossRef]

28. Liu, Z.; Yin, Z.; Chen, S.C.; Dai, S.; Huang, J.; Zheng, Q. Binary polymer composite dielectrics for flexible low-voltage organic field effect transistors. Org. Electron. 2018, 53, 205-212. [CrossRef]

29. Noh, Y.Y.; Sirringhaus, H. Ultra-thin polymer gate dielectrics for top-gate polymer field-effect transistors. Org. Electron. 2009, 10, 174-180. [CrossRef]

30. Cheng, X.; Caironi, M.; Noh, Y.Y.; Wang, J.; Newman, C.; Yan, H.; Facchetti, A.; Sirringhaus, H. Air Stable Cross-Linked Cytop Ultrathin Gate Dielectric for High Yield Low-Voltage Top-Gate Organic Field-Effect Transistors. Chem. Mater. 2010, 22, 1559-1566. [CrossRef]

31. Ha, Y.G.; Jeong, S.H.; Wu, J.S.; Kim, M.G.; Dravid, V.P.; Facchetti, A.; Marks, T.J. Flexible Low-Voltage Organic Thin-Film Transistors Enabled by Low-Temperature, Ambient Solution-Processable Inorganic/Organic Hybrid Gate Dielectrics. J. Am. Chem. Soc. 2010, 132, 17426-17434. [CrossRef] [PubMed]

32. Kim, S.H.; Hong, K.P.; Jang, M.; Jang, J.Y.; Anthony, J.E.; Yang, H.; Park, C.E. Photo-Curable Polymer Blend Dielectrics for Advancing Organic Field-Effect Transistor Applications. Adv. Mater. 2010, 22, 4809-4813. [CrossRef] [PubMed]

33. Vidor, F.F.; Meyers, T.; Hilleringmann, U. Inverter Circuits Using ZnO Nanoparticle Based Thin-Film Transistors for Flexible Electronic Applications. Nanomaterials 2016, 6, 154. [CrossRef] [PubMed]

34. Li, S.; Zhang, Q. The dielectric properties of low temperature thermally cross-linked polystyrene and poly(methyl methacrylate) thin films. RSC Adv. 2015, 5, 28980. [CrossRef]

35. Li, S.; Feng, L.; Zhao, J.; Guo, X.; Zhang, Q. Low temperature cross-linked, high performance polymer gate dielectrics for solution-processed organic field-effect transistors. Polym. Chem. 2015, 6, 5884-5890. [CrossRef] 
36. Xu, W.; Guo, C.; Rhee, S.W. High performance organic field-effect transistors using cyanoethyl pullulan (CEP) high-k polymer cross-linked with trimethylolpropane triglycidyl ether (TTE) at low temperatures. J. Mater. Chem. C 2013, 1, 3955-3960. [CrossRef]

37. Yoon, M.H.; Yan, H.; Facchetti, A.; Marks, T.J. Low-Voltage Organic Field-Effect Transistors and Inverters Enabled by Ultrathin Cross-Linked Polymers as Gate Dielectrics. J. Am. Chem. Soc. 2005, 127, 10388-10395. [CrossRef] [PubMed]

38. Li, S.; Tang, W.; Zhang, W.; Guo, X.; Zhang, Q. Cross-linked Polymer-Blend Gate Dielectrics through Thermal Click Chemistry. Chem. Eur. J. 2015, 21, 17762-17768. [CrossRef] [PubMed]

39. Lai, S.; Cosseddu, P.; Zucca, A.; Loi, A.; Bonfiglio, A. Combining inkjet printing and chemical vapor deposition for fabricating low voltage, organic field-effect transistors on flexible substrates. Thin Solid Films 2017, 631, 124-131. [CrossRef]

40. Leppaniemi, J.; Huttunen, O.H.; Majumdar, H.; Alastalo, A. Flexography-Printed $\mathrm{In}_{2} \mathrm{O}_{3}$ Semiconductor Layers for High Mobility Thin-Film Transistors on Flexible Plastic Substrate. Adv. Mater. 2015, 27, 7168-7175. [CrossRef] [PubMed]

41. Vidor, F.F.; Wirth, G.I.; Hilleringmann, U. Low temperature fabrication of a ZnO nanoparticle thin-film transistor suitable for flexible electronics. Microelectron. Reliab. 2014, 54, 2760-2765. [CrossRef]

42. Jung, S.Y.; Albariqi, M.; Gruntz, G.; Al-Hathal, T.; Peinado, A.; Garcia-Caurel, E.; Nicolas, Y.; Toupance, T.; Bonnassieux, Y.; Horowitz, G. A TIPS-TPDO-tetraCN-Based n-Type Organic Field-Effect Transistor with a Cross-linked PMMA Polymer Gate Dielectric. ACS Appl. Mater. Interfaces 2016, 8, 14701-14708. [CrossRef] [PubMed]

43. Ha, Y.G.; Emery, J.D.; Bedzyk, M.J.; Usta, H.; Facchetti, A.; Marks, T.J. Solution-Deposited Organic-Inorganic Hybrid Multilayer Gate Dielectrics. Design, Synthesis, Microstructures, and Electrical Properties with Thin-Film Transistors. J. Am. Chem. Soc. 2011, 133, 10239-10250. [CrossRef] [PubMed]

44. Wang, B.; Carlo, G.D.; Turrisi, R.; Zeng, L.; Stallings, K.; Huang, W.; Bedzyk, M.L.; Beverina, L.; Marks, T.J.; Facchetti, A. The Dipole Moment Inversion Effects in Self-Assembled Nanodielectrics for Organic Transistors. Chem. Mater. 2017, 29, 9974-9980. [CrossRef]

45. Kang, W.G.; An, G.I.; Kim, M.J.; Lee, W.H.; Lee, D.Y.; Kim, H.J.; Cho, J.H. Ladder-Type Silsesquioxane Copolymer Gate Dielectrics for High-Performance Organic Transistors and Inverters. J. Phys. Chem. C 2016, 120, 3501-3508. [CrossRef]

46. Kim, Y.T.; Roh, J.K.; Kim, J.H.; Kang, C.M.; Kang, I.N.; Jung, B.J.; Lee, C.H.; Hwang, D.H. Photocurable propyl-cinnamate-functionalized polyhedral oligomeric silsesquioxane as a gate dielectric for organic thin film transistors. Org. Electron. 2013, 14, 2315-2323. [CrossRef]

47. Lee, D.H.; Jeong, H.D. Solution-Processed Gate Insulator of Ethylene-Bridged Silsesquioxnae for Organic Field-Effect Transistor. J. Chosun Nat. Sci. 2010, 3, 7-18.

48. Hamada, T.; Nagase, T.; Kobayashi, T.; Matsukawa, K.; Naito, H. Effective control of surface property on poly(silsesquioxane) films by chemical modification. Thin Solid Films 2008, 517, 1335-1339. [CrossRef]

49. Choi, S.S.; Lee, A.S.; Lee, H.S.; Jeon, H.Y.; Baek, K.Y.; Choi, D.H.; Hwang, S.S. Synthesis and Characterization of UV-Curable Ladder-Like Polysilsesquioxane. J. Polym. Sci. Part A Polym. Chem. 2011, 49, 5012-5018. [CrossRef]

50. Park, E.S.; Ro, H.W.; Nguyen, C.V.; Jaffe, R.L.; Yoon, D.Y. Infrared Spectroscopy Study of Microstructures of Poly-(silsesquioxane)s. Chem. Mater. 2008, 20, 1548-1554. [CrossRef]

51. Ni, Y.; Zheng, S. A Novel Photocrosslinkable Polyhedral Oligomeric Silsesquioxane and Its Nanocomposites with Poly(vinyl cinnamate). Chem. Mater. 2004, 16, 5141-5148. [CrossRef]

(C) 2018 by the authors. Licensee MDPI, Basel, Switzerland. This article is an open access article distributed under the terms and conditions of the Creative Commons Attribution (CC BY) license (http://creativecommons.org/licenses/by/4.0/). 